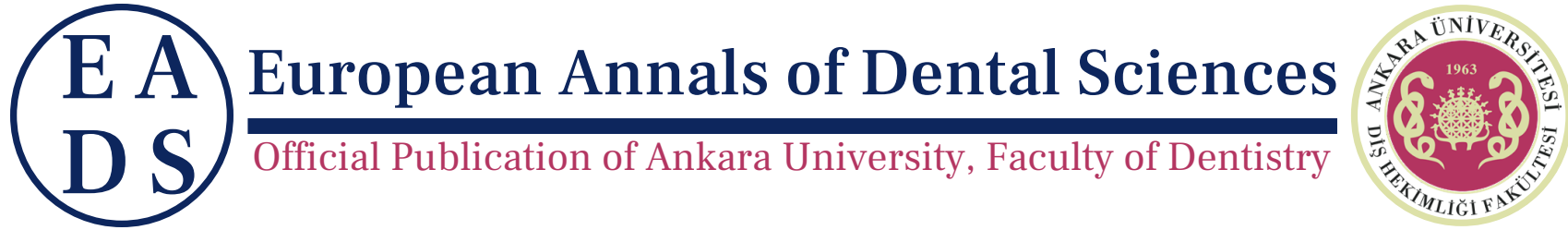

EADS, 2021, 48 (1), 84-87

\title{
Adenomatoid Hyperplasia of The Oral Cavity: A Diagnostic Dilemma
}

\author{
Ali Altındağ $\odot$, Poyzan Bozkurt $\odot 2, *$, Burak Bilecenoğlu 3 and Kaan \\ Orhan 4
}

\begin{abstract}
${ }^{1}$ DDS, Necmettin Erbakan University, Faculty of Dentistry, Department of Dentomaxillofacial Radiology, Konya, Turkey and ${ }^{2} \mathrm{DDS}, \mathrm{PhD}$, Ankara University, Faculty of Dentistry, Department of Oral and Maxillofacial Surgery, Ankara, Turkey and ${ }^{3} \mathrm{DDS}$, PhD, Ankara Medipol University, Faculty of Medicine, Department of Anatomy, Ankara, Turkey and 4DDS, PhD, Ankara University, Faculty of Dentistry, Department of Dentomaxillofacial Radiology, Ankara, Turkey

*Corresponding Author; poyzanbozkurt@hotmail.com
\end{abstract}

\begin{abstract}
This review study presents literature review and discusses the clinical significance of Adenomatoid Hyperplasia, a commonly misdiagnosed lesion. This rare entity has been seldom presented and is not well enough described in the literature. Only 15 reports with 95 cases could be attained during the online literature search using the keywords: Adenomatoid, Tumor, Hyperplasia, Minor salivary Glands. Data revealed a tendency towards the male gender. Age distribution of patients did not reveal a tendency towards a specific age group but presented a peak incidence in the 4 th and 5 th decades. Location data revealed a tendency towards the palate, especially the hard palate. Most of the presented cases were asymptomatic and the most common initial diagnosis made was salivary gland tumor. It was concluded that, adenomatoid hyperplasia of the oral cavity may resemble a wide range of pathologies and in order to differentiate and to achieve a correct diagnosis, histological evaluation is fundamental.
\end{abstract}

Key words: Adenomatoid Hyperplasia; Adenomatoid Tumor; Hyperplasia; Minor salivary Glands

\section{Introduction}

Minor salivary glands, which is responsible $\% 5$ of daily saliva secretion, are found on the walls of the oral cavity and named as labial, buccal, palatal, lingual, minor sublingual, palatoglossal and Ebner glands. Labial glands are found between the oral mucosa and orbicularis oris muscle of lips. Their secretion is directly drained into the oral vestibule. Buccal glands are located between the mucosa lining of cheeks and buccinator muscle. Some of these glands are found around the opening of the parotid gland and sometimes visible are called molar glands. These glands are mixed mucous and serous glands. There has been a wide variety of pathology related to minor salivary glands in which Adenomatoid hyperplasia $(\mathrm{AH})$ is one these pathologies. ${ }^{1,2}$

AH has been initially reported by Giansanti et al. in 1971 . $^{3}$ Till today AH remain to be an uncommon hyperplastic lesion; comprising neoplasm-resembling lesions. ${ }^{4}$ The etiology of $\mathrm{AH}$ is unknown; although it is thought that chronic local trauma may have a role. ${ }^{5}$ It usually presents as bluish or reddish, asymptomatic masses or elevated nodules. ${ }^{6}$ It may occur in all salivary gland-bearing areas of the body; in addition, reported cases concerning the oral cavity present the palate as the preferred site of occurrence. ${ }^{7}$ Histologically it presents no abnormality other than an apparent hyperplasia of the salivary gland tissue and after adequate surgical excision of this benign lesion recurrence is not expected. ${ }^{5}$ Its resemblance to pleomorphic adenomas and salivary gland tumors makes the lesion clinically important. 4

\section{Literature Review}

The local IRB granted exemption in writing, due to the study's retrospective nature. Data collection was made in PubMed, Science Direct and Google Scholar databases with the keywords 


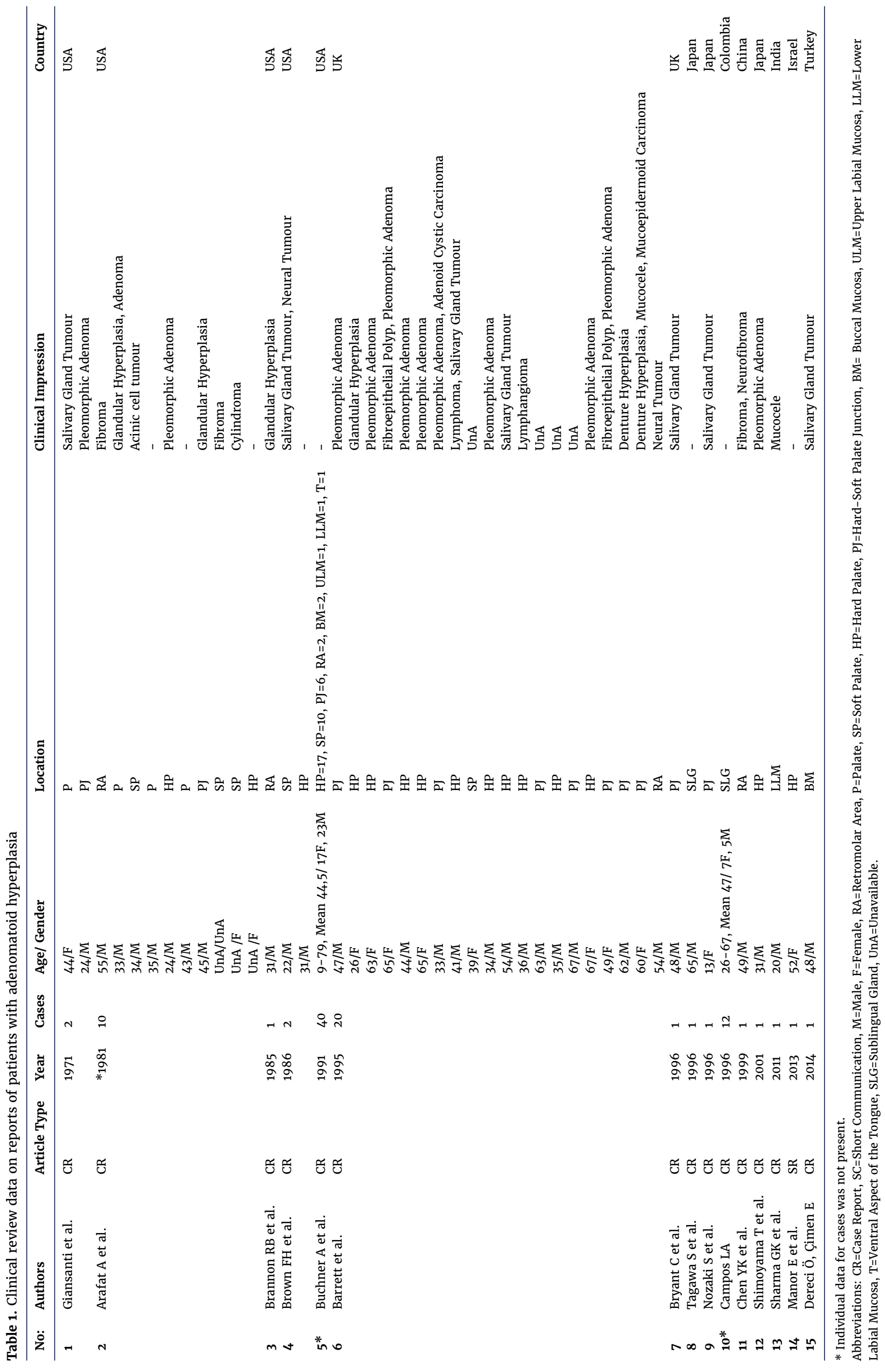


'adenomatoid', 'adenomatoid hyperplasia', 'Salivary gland', 'Minor salivary gland' keywords. Articles only in English language and reports on humans have been selected for the study. Since 1971, to the best of our knowledge, only 15 case reports, presenting 95 individual cases have been published in the English-language literature (Table 1). ${ }^{3-17} \mathrm{~A}$ new case has also been added to previously existing data. The review revealed 24 papers, of these papers, 8 could not be fully accessed ${ }^{18-24}$, one was related to the subject 'Adenomatoid Ductal Proliferation' 25 and one involved macaque monkeys. ${ }^{26}$

Adenomatoid hyperplasia of the minor salivary glands is an uncommonly reported entity in literature. The majority of cases were presented from the USA ( 55 cases), followed by the UK ( 21 cases), Colombia (12 cases), Japan (3 cases), Turkey, China, India, Israel (1 case). Nevertheless, a great number of literature in Japanese was also present in literature.

Gender distribution revealed patients to be $39.58 \%$ female (38 patients) and 59.37\% male (57 patients); for 1 patient $(1.04 \%)$ gender data was not available. This data revealed a tendency towards the male gender concerning $\mathrm{AH}$.

\section{Features of the Lesion}

Age distribution revealed patients to be $1 \%$ between the age range of $0-9,4.3 \%$ between the age range of $10-19,8.3 \%$ between the age range of $20-29,19.8 \%$ between the age range of $30-39,18.7 \%$ between the age range of $40-49,13.5 \%$ between the age range of $50-59,16.7 \%$ between the age range of $60-69$ and $2 \%$ between the age range of $70-79$. For three patients $(3.1 \%)$ age data was not present. For the remaining 12 patients $(12.5 \%)$ presented by Campos et al. (13), age data was not present for each individual case but the age range for cases was explained as 26-67 years with a mean of 47 years. This data revealed a higher frequency in the in the 4th, 5th, 6th and 7th decades of life compared to other age groups. Although this data did not reveal a tendency towards a specific age group it presented a peak incidence in the 4 th and 5 th decades.

Data concerning locations of the AHs revealed the lesion as $6.3 \%$ in the retromolar area, $71.9 \%$ on the palate (presented as $4.2 \%$ palate, $15.6 \%$ soft palate, $33.3 \%$ hard palate, $18.8 \%$ hard-soft palate junction), $4.2 \%$ on the buccal mucosa, $1 \%$ on the upper labial mucosa, $2 \%$ on the lower labial mucosa and $13.5 \%$ in the sublingual gland. This data revealed that $\mathrm{AH}$ had a tendency towards locating itself on the palate, especially the hard palate.

\section{Differential Diagnosis}

Among the presented cases, the most common initial diagnosis made was salivary gland tumor involving benign pleomorphic adenoma and adenoma, and malignant mucoepidermoid carcinoma and adenoid cystic carcinoma (21 cases). Salivary gland tumors occur much more commonly in the major glands (80$85 \%)$ and the majority is of benign nature (75-80\% for major glands, $50-55 \%$ for minor glands). ${ }^{27}$ Pleomorphic adenoma (PA) is a benign, mixed and most commonly encountered salivary gland tumor. It is a slow-growing, painless mass, commonly occurring in the 5 th decade of life with a predilection to the female gender. Although the most common localization of PA is the major salivary glands, especially the parotid gland $(>80 \%)$, it may also appear in the minor salivary glands with the palate being the most common intraoral site. ${ }^{27}$ With its clinical features very much resembling to $\mathrm{AH}$, it was the most common initial diagnosis made among salivary gland tumors (11 cases).

When clinical impressions were evaluated, it was observed that other differential diagnosis of AHs involved fibroma, acinic cell tumor, cylindroma, fibroepithelial polyp, lymphoma and lymphangioma, denture hyperplasia, mucocele, and neurofibroma and neural tumor.

Although some cases referred with pain and tenderness, most of the presented cases were asymptomatic. Data of smoking habits and present dentures were not present for most cases.

As result of the present literature review it was concluded that $\mathrm{AH}$ of the oral cavity is a rare entity mostly occurring in male gender at the 4th and 5th decades of life, commonly presenting as asymptomatic masses and have a predilection to be localized at the palate. With these features, they may resemble a wide range of benign and malign pathologies. In order to differentiate the lesion from these wide ranges of pathologies and to achieve a correct diagnosis, histological evaluation is fundamental.

\section{Author Contributions}

All authors have contributed to; conception and design of the study, data collection and analysis, writing the manuscript, approval of the final version to be submitted.

\section{Conflict of Interest}

Authors declare no Conflict of Interests for this article.

\section{Authors' ORCID(s)}
A.A. $\quad 0000-0001-8549-5193$
P.B. $0000-0001-6752-3998$
B.B. $0000-0001-7097-1572$
K.O. $0000-0001-6768-0176$

\section{References}

1. Moore KL, Dalley AF, Agur AMR. Clinically oriented anatomy; 2014.

2. Standring S. Gray's anatomy E-Book: the anatomical basis of clinical practice. Elsevier Health Sciences; 2020.

3. Giansanti JS, Baker GO, Waldron CA. Intraoral, mucinous, minor salivary gland lesions presenting clinically as tumors. Oral Surg Oral Med Oral Pathol. 1971;32(6):918-922. doi:10.1016/0030-4220(71)90179-4.

4. Manor E, Sinelnikov I, Brennan PA, Bodner L. Chromosomal aberrations in adenomatoid hyperplasia of palatal minor salivary gland. Br J Oral Maxillofac Surg. 2013;51(2):170-172. doi:10.1016/j.bjoms.2012.04.079.

5. Barrett AW, Speight PM. Adenomatoid hyperplasia of oral minor salivary glands. Oral Surg Oral Med Oral Pathol Oral Radiol Endod. 1995;79(4):482-487. doi:10.1016/S10792104(05)80132-5.

6. Arafat A, Brannon RB, Ellis GL. Adenomatoid hyperplasia of mucous salivary glands. Oral Surg Oral Med Oral Pathol. 1981;52(1):51-55. doi:10.1016/0030-4220(81)90172-9.

7. Brown FH, Houston GD, Lubow RM, Sagan MA. Adenomatoid Hyperplasia of Mucous Salivary Glands. J Periodontol. 1987;58(2):125-127. doi:10.1902/jop.1987.58.2.125.

8. Brannon RB, Houston GD, Meader CL. Adenomatoid hyperplasia of mucous salivary glands: A case involving the retromolar area. Oral Surg Oral Med Oral Pathol. 1985;60(2):188-190. doi:10.1016/0030-4220(85)90290-7. 
9. Bryant C, Manisali M, Barrett AW. Adenomatoid hyperplasia of palatal minor salivary glands. J Laryngol Otol. 1996;110(2):167-169. doi:10.1017/S0022215100133067.

10. Buchner A, Merrell PW, Carpenter WM, Leider AS. Adenomatoid hyperplasia of minor salivary glands. Oral Surg Oral Med Oral Pathol. 1991;71(5):583-587. doi:10.1016/00304220(91)90367-L.

11. Campos LA. Hyperplasia of the sublingual glands in adult patients. Oral Surg Oral Med Oral Pathol Oral Radiol Endod. 1996;81(5):584-585. doi:10.1016/S1079-2104(96)80052-7.

12. Chen YK, Lin CC, Lin LM, Yan YH. Adenomatoid hyperplasia in the mandibular retromolar area. Case report. Aust Dent J. 1999;44(2):135-136. doi:10.1111/j.18347819.1999.tboo215.x.

13. Dereci O, Cimen E. Adenomatoid hyperplasia of the minor salivary glands on the buccal mucosa: A rare case report. Int J Surg Case Rep. 2014;5(5):274-6. doi:10.1016/j.ijscr.2014.03.020.

14. Nozaki S, Araki A, Nakagawa K, Yamamoto E. Adenomatoid hyperplasia of the palate in an Asian child. J Oral Maxillofac Surg. 1996;54(5):627-628. doi:10.1016/S02782391(96)90647-3.

15. Sharma GK, Sharma M, Vanaki SS. Adenomatoid hyperplasia of lower lip. Dent Res J (Isfahan). 2011;8(4):226-8. doi:10.4103/1735-3327.86047.

16. Shimoyama T, Wakabayashi M, Kato T, Kaneko T, Horie $\mathrm{N}$, Ide $\mathrm{F}$. Adenomatoid hyperplasia of the palate mimicking clinically as a salivary gland tumor. J Oral Sci. 2001;43(2):135-138. doi:10.2334/josnusd.43.135.

17. Tagawa S, Inui M, Mori A, Seki Y, Murata T, Tagawa T. Adenomatoid serous hyperplasia of sublingual gland: A case report. Oral Surg Oral Med Oral Pathol Oral Radiol Endod. 1996;82(4):437-440. doi:10.1016/S1079-2104(96)80311-8.

18. Aufdemorte TB, Ramzy I, Holt GR, Thomas JR, Duncan DL.
Focal adenomatoid hyperplasia of salivary glands. A differential diagnostic problem in fine needle aspiration biopsy. Acta Cytol. 1985;29(1):23-28.

19. Carlos R, Aguirre JM, Pineda V. Asymptomatic posterolateral lingual mass. Oral Surg Oral Med Oral Pathol Oral Radiol Endod. 1999;88(6):654-656. doi:10.1016/S10792104(99)70003-X.

20. Devildos LR, Langlois CC. Minor salivary gland lesion presenting clinically as tumor. Oral Surg Oral Med Oral Pathol. 1976;41(5):657-659. doi:10.1016/0030-4220(76)90320-0.

21. Guallart Doménech F, Molina Mira A, González Martínez MA, Pons Rocher F, Mompó Romero L, Serrano Badía E. [Adenomatoid hyperplasia of minor salivary glands]. An Otorrinolaringol Ibero Am. 1994;21(3):275-80.

22. Petri WH, Carr RF, Kahn CS. Adenomatoid hyperplasia of the palate. J Oral Maxillofac Surg. 1993;51(3):310-311. doi:10.1016/S0278-2391(10)80181-8.

23. Scully C, Eveson JW, Richards A. Adenomatoid hyperplasia in the palate: another sheep in wolf's clothing. Br Dent J. 1992;173(4):141-142. doi:10.1038/sj.bdj.4807969.

24. Tucci E, Pompa G, Massà R, Guerra F, Santilli D. [Adenomatoid hyperplasia of the minor salivary glands. Report of a clinical case]. Minerva Stomatol. 1996;45(1-2):49-52.

25. Luna MA. Salivary Gland Hyperplasia: On: Adenomatous ductal proliferation of the salivary gland. Yu G-Y, Donath K, Mult D. Oral Surg Oral Med Oral Pathol Oral Radiol Endod 2001;91:215-221. Adv Anat Pathol. 2002;9(4). doi:10.1097/00125480-200207000-00005.

26. Radi ZA, Morton DG. Lip salivary-gland hamartoma in a cynomolgus macaque (Macaca fascicularis). Comp Med. 2014;64(1):68-70.

27. Hupp JR, Tucker MR, Ellis E. Contemporary Oral and maxillofacial surgery-E-book. Elsevier Health Sciences; 2013. 